\title{
Analysis of trace elements released from glass ionomer restorative materials by inductively coupled plasma-mass spectrometry
}

\author{
Bilal Ozmen ( $\nabla$ bilalozmen@hotmail.com ) \\ Ondokuz Mayıs University \\ Emre Aksoy \\ Ondokuz Mayıs University
}

\section{Research Article}

Keywords: Compomer, Glass ionomer, Inductively coupled plasma-mass spectrometry, Trace element

Posted Date: February 23rd, 2021

DOI: https://doi.org/10.21203/rs.3.rs-236950/v1

License: () (7) This work is licensed under a Creative Commons Attribution 4.0 International License. Read Full License 


\section{Abstract \\ Background}

The aim of this study was to determine the amount of trace elements released from a traditional glass ionomer, a bulk-fill glass ionomer, a resin-modified glass ionomer, a glass carbomer fill and a compomer material stored in ultra-distilled water.

\section{Methods}

Ten cylindrical $(10 \times 2 \mathrm{~mm})$ specimens were prepared from each material. Each sample was stored in $50 \mathrm{~mL}$ ultra-distilled water at $37^{\circ} \mathrm{C}$ for fourteen days, and rinsed twice daily. The amount of elements in the solutions was determined using inductively coupled plasma-mass spectrometry.

\section{Results}

Aluminum, boron, nickel, copper, zinc, barium and lead were detected in all solutions. The traditional glass ionomer and resin-modified glass ionomer released arsenic, the bulk-fill glass ionomer and compomer released selenium, and the resin-modified glass ionomer and compomer released antimony. Only the resinmodified glass ionomer released iron.

\section{Conclusion}

All materials tested released some trace elements, but the rates were quite low. Therefore, these glass ionomer materials can be used safely in dentistry.

\section{Background}

Since their first introduction in the early 1970s [1], glass-ionomer cements (GICs), which consist of a powder (fluoroaluminosilicate glass) and a liquid (polyacrylic acid), have been widely used in dentistry because of a number of suitable properties, such as chemical diffusion-based adhesion to enamel and dentine [2], fluoride release [3], and biological compatibility [4]. However, they have some drawbacks, such as poor strength, early water sensitivity and reduced occlusal wear resistance. Therefore, the use of GICs is limited in high-stress sites and large posterior cavities [5].

Many attempts have been made to improve the mechanical properties of conventional GICs. As a result, resin-modified GICs, high viscosity GICs and metalreinforced GICs have been developed [6]. In metal-reinforced GIC, metal dust is added to the powder component, and in high viscosity GIC, the powder: liquid ratio is changed [6-8]. Resin-modified GIC has a glass ionomer and resin composite chemistry, and is set through an acid-base reaction and polymerization with light [9-11]. Resin-modified GICs have good physical properties due to the incorporation of water-soluble resin monomers into an aqueous solution of polyacrylic acid, while retaining the basic features of conventional GICs [4, 9-11].

Glass carbomer fill ${ }^{\mathrm{TM}}$ (GCF) is a novel restorative filling material that incorporates fluoride and nano-hydroxyapatite particles. The manufacturer claims that GCF exhibits excellent clinical performance and is superior to many traditional high-viscosity GICs because of its nano-sized powder particles and the fluoride-hydroxyapatite structure $[12,13]$. They also claim that the material becomes stronger when the total particle surface in contact with the glasscarbomer liquid increases [12, 13].

Compomers or polyacid-modified composite resins are widely used in primary tooth restorations, and are formed by combining glass ionomer and composite resin materials. Fluoride release, superior aesthetic properties, color options and polymerization with light are some of their important properties [14].

GICs and compomers are known sources of low fluoride release to the oral environment. The highest fluoride release from these materials is within the first week [15]. In addition to fluoride, other elements and ions can be released from GICs into the ambient solution after setting [3, 16]. The elements and ions released from these materials may be useful for secondary caries prevention, remineralization and prevention of bacterial colonization. However, some elements (arsenic, lead, etc.) are heavy metals, and their presence in dental materials may cause adverse health effects, young children being particularly at risk [17-20].

An extensive review of the literature yielded little information on the amount of trace elements released from restorative dental materials. The aim of this study is to compare the amount of trace elements released from a traditional glass ionomer (TGI), a bulk-fill glass ionomer (BFGI), a resin-modified glass ionomer (RMGI), a glass carbomer fill (GCF), and a compomer. Inductively coupled plasma-mass spectrometry (ICP-MS) was used for the analysis of toxic and trace elements because of its accepted advantages of sensitivity, selectivity and multi-element analytical capability [20]. In addition, the pH and electrical conductivity of each material were evaluated. The null hypothesis was that the amount of trace elements released did not differ significantly between the types of glass ionomer.

\section{Methods}

\section{Sample preparation}

Four different capsuled glass ionomer restorative materials, TGI (Riva Self Cure, SDI Limited, Bayswater, VIC, Australia), BFGI (EQUIA Forte ${ }^{\circledR}$, GC Corporation, Tokyo, Japan), RMGI (Photac Fil Quick Aplicap ${ }^{T M}$, 3M ESPE, St. Paul, MN USA), and GCF (GCP Dental, Ridderkerk, Netherlands), and a compomer (Glasiosite 
Caps, VOCO GmbH, Cuxhaven, Germany) were tested in this study (Table 1). Ten cylindrical specimens, $10 \mathrm{~mm}$ in width and $2 \mathrm{~mm}$ in depth, were prepared from each material according to the manufacturer's instruction at $23 \pm 2^{\circ} \mathrm{C}$ [8]. A syg-200 dental amalgamator (Smaco Company, Hangzhou Zhejiang, China) was

used as a mixing device. The light-curing devices used for polymerization are shown in Table 2 . The samples were kept at $95 \%$ humidity and $37^{\circ} \mathrm{C}$ for 24 hours $[3,8]$. Then, each sample was placed in a sterile polypropylene tube with a cover, and $50 \mathrm{ml}$ of ultra-distilled water (18M $\Omega . \mathrm{cm})$ was added. All samples were stored at $37^{\circ} \mathrm{C}$ for fourteen days. Each tube was rinsed twice daily. After 14 days, the samples were removed from the solutions, and the latter were analyzed for trace elements using ICP-MS.

\section{Elemental analysis}

An inductively coupled plasma-mass spectrometer (Agilent 7700, Agilent, Santa Clara, USA) was used to measure the levels of trace elements released from the five different dental materials. First, device validation was performed with standard mixtures (High-Purity Standards, North Charleston, USA). The standard mixtures and ultra-distilled water were injected into the device, and calibration lines were obtained. Second, the solutions were sent to the mass spectrometer after ionization in inductively coupled plasma and measured as mass-to-charge ratio [20]. The basic principle was that solutions were ionized by argon plasma which was brought to a temperature of $10,000 \mathrm{~K}$ by electromagnetic induction. The amounts of the elements were measured with an electron augmentation detector. The reactive materials were ultra-distilled water ( $18 \mathrm{M \Omega} . \mathrm{cm}), 60 \%$ ultrapure nitric acid at a density of $1.37 \mathrm{~kg} / \mathrm{L}, 30 \% \mathrm{hydrochloric}$ acid at a density of $1.15 \mathrm{~kg} / \mathrm{L}, 5 \%$ nitric acid washing solution and a blank solution ( $0.5 \%$ nitric acid). The amount of each element was determined as parts per billion (ppb or $\mu \mathrm{g} / \mathrm{L}$ ). The laboratory temperature was $23 \pm 2^{\circ} \mathrm{C}$ degrees.

\section{pH measurements}

The $\mathrm{pH}$ of each solution was measured with a pH meter (WTW InoLab-IDS multi 720, Probe 325). For pH measurements, device validation was performed first using solutions with standard pH ( $\mathrm{pH} \mathrm{4,7}$ and 10; Certipur buffer solutions, Merck KGaA, Darmatadt, Germany). Then, the device probe was held in the test solution until the $\mathrm{pH}$ was stabilized. The $\mathrm{pH}$ value was then recorded. Before each subsequent measurement, the probe was washed with distilled water and dried with a napkin.

\section{Electrical conductivity measurements}

The electrical conductivity of each solution was measured with a meter (WTW InoLab-IDS multi 9310, Probe 925). First, device validation was performed with solutions with standard conductivity (electrical conductivity of $12.85 \pm 4 \% \mathrm{mS} / \mathrm{cm}$ and $1412 \pm 5 \% \mu \mathrm{S} / \mathrm{cm}$; Certipur potassium chloride solution, Merck KGaA, Darmatadt, Germany). Second, the device probe was placed in the test solution until conductivity was stabilized, and the value was then recorded. Before each subsequent measurement, the probe was washed with distilled water and dried with a napkin.

\section{Statistical analysis}

The data were statistically analyzed using one-way analysis of variance, Duncan's multiple range test and independent samples t-test for two-group comparisons (SPSS 17 for Windows, SPSS Inc., Chicago, IL, USA) with the significance level set at $p<0.05$.

\section{Results}

The mean and standard deviation of the amount of each element released are shown in Table 3. Boron, aluminum, nickel, copper, zinc, barium and lead were released from each material $(p<0.05)$. BFGI and the compomer released selenium $(p>0.05)$. RMGI and the compomer released antimony $(p>0.05)$. TGI and RMGI released arsenic $(\mathrm{p}<0.001)$. Only RMGI released iron.

The lowest $\mathrm{pH}$ was observed in the compomer group $(\mathrm{p}<0.001)$; the $\mathrm{pH}$ values of the other groups were similar (Table 4). The electrical conductivities of solutions were significantly different between groups $(\mathrm{p}<0.001$; Table 4$)$. The highest electrical conductivity value was observed in the RMGI group.

\section{Discussion}

GICs are used for different purposes, such as restorative filling, pit-and-fissure sealing, luting, lining, and as base cements [4]. However, they have been modified, mainly by the addition of resin components, to improve their mechanical properties, without an adequate evaluation of fluoride release [3, 8]. In GICs, there is an acid-base reaction resulting in the leaching of fluoride ions to form a polysalt matrix [4]. In addition, unreacted glass particles may cause rapid release after mixing [21] which may be responsible for the fast elution process. This phenomenon is known as the 'burst effect' [15]. There is also a much smaller but steady release that can last for a long period [8]. These release processes may also be true for other elements. Previous studies have shown that dental materials can release some heavy metals [17-19,22]. The inclusion of heavy metals in dental materials raises concerns because most dental materials are in contact with both soft and hard tissue [17]. Therefore, dental materials should not contain heavy metals or heavy metals should not be released into the mouth. This study showed that boron, aluminum, iron, nickel, copper, zinc, arsenic, selenium, antimony, barium and lead were released from glass ionomers. When all the results of the study were considered together, there were statistically significant differences between glass ionomer types. Therefore, the null hypothesis was rejected.

In release studies, different storage media, such as artificial saliva, human saliva, saline, acidic solutions, and deionized water, have often been used [15, 23]. Some studies have suggested that saliva or $\mathrm{pH}$-cycling models may better simulate the oral environment and, consequently, be more appropriate for studying ion release from dental materials. However, the use of ultra-distilled water is considered to give an accurate estimate of the ions released since there are no existing ions in this medium [24]. Ultra-distilled water is acceptable as a storage medium for in vitro studies, and, in this study, it was preferred for release of all 
elements. The number of samples in previous studies $[15,25]$ was limited to three or six. This study attempted to obtain more precise results by increasing the number of samples.

ICP-MS is an appropriate method for identifying less frequently observed elements, and provides highly accurate results even if the sample size is small. In this method, plasma reaches a high temperature (nearly 10,000K) at which metals and metalloids are ionized, making them detectable on a mass detector [26]. Some researchers have used inductively coupled plasma-atomic emission spectrometry [22] while others prefer inductively coupled plasma-optical emission spectrometry [19] for detecting trace elements inside different types of mineral trioxide aggregate. All methods are suitable for determining trace elements in dental materials. Following previous studies $[17,27]$ ICP-MS was used in this study.

A number of studies have reported $[15,28,29]$ that the highest ion release from GICs was within the first week and ion release was reduced to constant levels at about 14 days. Therefore, this study determined the cumulative number of elements released over 14 days. Although the same conditions (temperature, specimen geometry, storage medium and polishing procedure) were maintained for all samples, differences were observed in the amounts of elements released. These findings may be related to multiple factors, such as the chemical and physical characteristics of the GICs, powder: liquid ratio, solubility of glass particles, mixing time and type of polymerization [8-29].

Kuhn and Wilson suggested three mechanisms for fluoride release from GICs: diffusion through pores and microfractures, mass diffusion and superficial rinse [30]. Superficial rinse can be related to the particle size of GICs. Glass particles are milled under dry conditions to a size less than $20 \mu \mathrm{m}$. As a result, the surface may be coated with a fine dust that can be washed off and dissolved when in contact with the ambient solution. Other release mechanisms may be related to long-term release processes. GICs absorb water over time, and ion release may occur from the cracks and body of GICs and require more time than conjectured. Similar phenomena may be true for release of elements in this study. However, depending on the differences in the content of the materials, not all element can be released from each type of glass ionomer. In this study, little iron, nickel, copper, arsenic, selenium, antimony and lead release was found; in contrast, aluminum, boron, barium and zinc were released at a higher rate.

Antibacterial activity of fluoride and alumino-fluoro complexes is important against cariogenic microorganisms $[3,17]$. However, aluminum is a heavy metal, and high exposure to it may cause neurotoxicity, and may play a role, in addition to genetic factors, in the development of Alzheimer's disease [31]. Moreover, inclusion of aluminum is not indicated in dental materials and other biomaterials owing to the risk of Alzheimer's disease from excessive exposure to the element in close contact with human tissue [16]. Gjorgievska et al. detected aluminum (10.6-26.3ppm) using atomic absorption spectrophotometry in four different dental materials (TGI, RMGI, compomer and composite) [16]. They reported that TGI generally released more aluminum than RMGI [16]. In this study, all groups released aluminum, as also found in previous studies $[3,16]$, and the element with the highest level of release was aluminum $(0.08-4.42 \mathrm{mg} / \mathrm{L})$. RMGI released more aluminum than the other glass ionomers. This finding agrees with that of Okte et al. [3]. The larger pore size and greater porosity of RMGI in comparison to TGI may explain the difference in the level of release of aluminum from the glass particles [16]. The average intake from food is 10mg/day [32]. The amounts obtained in this study are far below the daily consumption of the element. Hence, the amount of aluminum released from glass ionomers is acceptable and poses no threat to human health.

Boron is a ubiquitous non-essential element in the human body and is part of many biochemical and metabolic functions beneficial to human health and wellbeing [33]. People consume many products (vegetables, fruits, nuts, etc.) containing boron in daily life. The acceptable safe range of boron in food is $1-$ $7 \mathrm{mg} /$ day. In healthy people, boron levels change between 15 and $80 \mu \mathrm{g} / \mathrm{kg}$ [34]. In this study, boron showed the second highest release from glass ionomers. The highest amount released (1221ppb) was in GCF and the lowest (7.86ppb) was in RMGI. The amount of boron released from GICs is not at a level that can be harmful to humans.

Barium is a heavy metal and is found in many types of food and beverages. González-Weller et al. demonstrated that barium intake in individuals from different regions was nearly $0.6-0.7 \mathrm{mg} /$ day [35]. Barium sulfate is often used as a radiopaque agent in the composition of various dental materials [36]. The effects of barium sulfate are debatable. Sabokbar et al. reported that it was not adequate to prevent bone resorption [37]. However, Khandaker et al. suggested that barium sulphate may be biologically useful [36]. In this study, barium was released at the highest amount in the compomer group (193.7ppb) and at the lowest $(0.8 \mathrm{ppb})$ in the TGI group. More barium may be added to compomers for opacity or compomers can release more barium independently of opacity.

Zinc is not stored in the body, but must be obtained from dietary sources. It has catalytic, structural, and regulatory functions in the body, participates in many enzymatic activities and has an anticancer role. Zinc deficiency is a major health problem, affecting over two billion people worldwide [38]. The daily recommendation for men is $11 \mathrm{mg}$ and for women $8 \mathrm{mg}$ [39]. In this study, all materials released zinc and the amounts released (0.57-6.82ppb) were much less than the recommended daily dose. The lowest zinc release was detected in BFGI and the highest in RMGI.

In this study, iron was detected only in the RMGI group (0.43ppb). Antimony was determined in two groups, at $4.73 \mathrm{ppb}$ in the compomer and at $0.09 \mathrm{ppb}$ in RMGI. Selenium was released in BFGI $(0.16 \mathrm{ppb})$ and the compomer $(0.24 \mathrm{ppb})$. Very small amounts of nickel $(0.12-0.41 \mathrm{ppb})$ and copper $(0.21-1.18 \mathrm{ppb})$ were observed in all groups. The amounts detected were far from the rates that threaten general health. It is believed that these metals may play a role in the hardening reactions of glass ionomers.

Previous studies have shown that some dental materials may contain toxic trace elements such as arsenic and lead [17-20, 22]. Arsenic is a metalloid element and a poison. Arsenic toxicity results in multisystem disease. The European Food Safety Authority has estimated that a 70-kg adult consumes an average of $9.1-39.2 \mu \mathrm{g}$ of arsenic daily [40]. Lead, just like arsenic, is a known neurotoxic metal and lead toxicity is a major public health problem in all countries. Acute or chronic lead exposure has the potential to cause many deleterious effects in the cardiovascular, renal, nervous, immune, and gastrointestinal systems. A lead level of $\geq 5 \mu \mathrm{g} / \mathrm{dL}$ in the blood is considered high for adults and children [41]. In this study, lead release was observed in all glass ionomers: RMGI $(0.44 \mathrm{ppb})>\mathrm{TGI}(0.41 \mathrm{ppb})>\mathrm{BFGI}(0.35 \mathrm{ppb})>$ compomer $(0.16 \mathrm{ppb})>\mathrm{GCF}(0.14 \mathrm{ppb})$. Detectable levels of arsenic were observed in TGI and RMGI at $0.38 \mathrm{ppb}$ and $0.10 \mathrm{ppb}$, respectively. The lead and arsenic release were negligible, and was considerably lower than in previous studies $[17,18,20]$. 
Camilleri et al. identified lead and arsenic in five different dental cements kept in two different solutions (acid and Hank's balanced salt solution) [17]. They stated that the quantity of acid-extractable trace elements was high for most of the materials tested, but little was released in the balanced salt solution. They reported that arsenic concentrations were $0.08-52.5 \mathrm{mg} / \mathrm{kg}$ and lead concentrations were $0.03-14.5 \mathrm{mg} / \mathrm{kg}$ [17]. Simsek et al. investigated the accumulation of trace elements, such as lead and arsenic, inside the organs of rats using three different dental materials (Mineral trioxide aggregate, BioAggregate and Biodentine) [20]. They found both arsenic $(0.9-21.9 \mu \mathrm{g} / \mathrm{kg})$ and lead $(0.4-2.9 \mu \mathrm{g} / \mathrm{kg})$ release from all materials, and detected these substances in the brain, kidney and liver of rats [20]. Similarly, Jang et al. evaluated the release of nine heavy metals from three dental materials, and reported lead (1.1-1.9ppb) and arsenic $(0.1-9.3 \mathrm{ppb})$ release from all materials. The researchers concluded that cements were reliable materials for dental treatment [18].

Electrical conductivity is closely correlated to the number of ions in the solution. In this study, RMGI had the highest electrical conductivity. The lowest pH was observed in the compomer, whereas the other groups had similar pH values. Hardening occurs in TGIs chemically, in RMGIs with light, and in GCF with both light and heat. These differences may have affected the amounts of elements released from the glass ionomers and their electrical conductivity and pH.

\section{Conclusion}

This study demonstrated that all dental materials tested - glass ionomers and compomer - released some trace elements, but the rates were quite low. Therefore, these materials should be considered safe to use. Elements such as lead and arsenic, which are known to be toxic and harmful to humans, should be eliminated from dental materials or their release to the body should be prevented. The composition and chemical and physical characteristics of glass ionomers are important for release of elements, $\mathrm{pH}$ and electrical conductivity. The type of polymerization (chemical, light or light and heat) of glass ionomers can also have an impact on the release of elements. There is a need for further in vitro studies, using different materials, different periods of experimentation and storage media, or clinical trials.

\section{Abbreviations}

BFGI: Bulk-fill glass ionomer; GCF:Glass carbomer fill; GICs: Glass-ionomer cements;

ICP-MS: Inductively coupled plasma-mass spectrometry; RMGI: Resin-modified glass ionomer; TGI: Traditional glass ionomer;

\section{Declarations}

\section{Ethics approval and consent to participate}

Not applicable.

\section{Consent for publication}

Not applicable.

\section{Competing interests}

The authors declare that they have no competing interests.

\section{Funding}

No financial support was received for this research.

\section{Authors' contributions}

BO was supervisors and principal investigators of the study and drafted the manuscript. EA and BO revised the manuscript. All authors read and approved the final version of the manuscript.

\section{Availability of data and materials}

The datasets generated during and/or analysed during the current study are available from the corresponding author on reasonable request

\section{Acknowledgements}

The author thanks the Samsun Public Health Directorate for laboratory services and Samet Hasan Abaci for his guidance on statistical analysis.

\section{Author's information}

${ }^{1}$ Research Fellow, DDS, Ph.D., Department of Pediatric Dentistry, Faculty of Dentistry, Ondokuz Mayis University, Samsun, Turkey

${ }^{2}$ Research Associate, DDS, Department of Pediatric Dentistry, Faculty of Dentistry, Ondokuz Mayis University, Samsun, Turkey

\section{References}

1) Wilson AD, Kent BE. A new translucent cement for dentistry. The glass ionomer cement. Br Dent J 1972; 132(4): 133-135. 
2) Hosoya Y, García-Godoy F. Bonding mechanism of Ketac-Molar Aplicap and Fuji IX GP to enamel and dentin. Am J Dent 1998; 11(5): $235-239$.

3) Okte Z, Bayrak S, Fidanci UR, Sel T. Fluoride and aluminum release from restorative materials using ion chromatography. J Appl Oral Sci 2012; 20(1): 27-31.

4) Sidhu SK. Glass-ionomer cement restorative materials: a sticky subject? Aust Dent J 2011; 56 Suppl 1: 23-30.

5) Sunnegårdh-Grönberg K, Peutzfeldt A, van Dijken JW. Hardness and in vitro wear of a novel ceramic restorative cement. Eur J Oral Sci 2002; $110(2)$ : 175-8.

6) Nicholson JW. Chemistry of glass-ionomer cements: a review. Biomaterials 1998; 19(6): 485-494.

7) Guggenberger R, May R, Stefan KP. New trends in glass-ionomer chemistry. Biomaterials 1998; 19(6): 479-483.

8) Shiozawa M, Takahashi $\mathrm{H}$, Iwasaki N. Fluoride release and mechanical properties after 1-year water storage of recent restorative glass ionomer cements. Clin Oral Investig 2014; 18(4): 1053-1060.

9) Wilson AD. Resin-modified glass-ionomer cements. Int J Prosthodont 1990; 3(5): 425-429.

10) Mitra SB. Adhesion to dentin and physical properties of a light-cured glass-ionomer liner/base. J Dent Res 1991; 70(1): 72-74.

11) McCabe JF. Resin-modified glass-ionomers. Biomaterials 1998; 19(6): 521-527.

12) Koenraads H, Van der Kroon G, Frencken JE. Compressive strength of two newly developed glass-ionomer materials for use with the Atraumatic Restorative Treatment (ART) approach in class II cavities. Dent Mater 2009; 25(4): 551-556.

13) Chen X, Cuijpers V, Fan M, Frencken JE. Marginal leakage of two newer glass-ionomer-based sealant materials assessed using micro-CT. J Dent 2010; 38(9): 731-735.

14) Nicholson JW. Polyacid-modified composite resins ("compomers") and their use in clinical dentistry. Dent Mater 2007; 23(5): 615-622.

15) Garcez RM, Buzalaf MA, de Araújo PA. Fluoride release of six restorative materials in water and pH-cycling solutions. J Appl Oral Sci 2007; 15(5): 406411.

16) Gjorgievska E, Nicholson JW, Gjorgovski I, Iljovska S. Aluminium and fluoride release into artificial saliva from dental restoratives placed in teeth. J Mater Sci Mater Med 2008; 19(10): 3163-3167.

17) Camilleri J, Kralj P, Veber M, Sinagra E. Characterization and analyses of acid-extractable and leached trace elements in dental cements. Int Endod J 2012; 45(8): 737-43.

18) Jang YE, Lee BN, Koh JT, Park YJ, Joo NE, Chang HS, et al. Cytotoxicity and physical properties of tricalcium silicate-based endodontic materials. Restor Dent Endod 2014; 39(2): 89-94.

19) Kum KY, Kim EC, Yoo YJ, Zhu Q, Safavi K, Bae KS, et al. Trace metal contents of three tricalcium silicate materials: MTA Angelus, Micro Mega MTA and Bioaggregate. Int Endod J 2014; 47(7): 704-710.

20) Simsek N, Bulut ET, Ahmetoğlu F, Alan H. Determination of trace elements in rat organs implanted with endodontic repair materials by ICP-MS. J Mater Sci Mater Med 2016; 27(3): 46.

21) Gandolfi MG, Chersoni S, Acquaviva GL, Piana G, Prati C, Mongiorgi R. Fluoride release and absorption at different pH from glass-ionomer cements. Dent Mater 2006; 22(5): 441-449.

22) Chang SW, Shon WJ, Lee W, Kum KY, Baek SH, Bae KS. Analysis of heavy metal contents in gray and white MTA and 2 kinds of Portland cement: a preliminary study. Oral Surg Oral Med Oral Pathol Oral Radiol Endod 2010; 109(4): 642-6.

23) McKenzie M.A, Linden RW, Nicholson JW. The physical properties of conventional and resin-modified glass-ionomer dental cements stored in saliva, proprietary acidic beverages, saline and water. Biomaterials 2003; 24(22): 4063-4069.

24) Neelakantan P, John S, Anand S, Sureshbabu N, Subbarao C. Fluoride release from a new glass-ionomer cement. Oper Dent 2011; 36(1): 80-85.

25) Chan WD, Yang L, Wan W, Rizkalla AS. Fluoride release from dental cements and composites: a mechanistic study. Dent Mater 2006; 22(4): 366-373.

26) Goullé JP, Mahieu L, Castermant J, Neveu N, Bonneau L, Lainé G, et al. Metal and metalloid multi-elementary ICP-MS validation in whole blood, plasma, urine and hair. Reference values. Forensic Sci Int 2005; 4;153(1):39-44.

27) Yalçın SS, Çak T, Yalçın S. Lower strontium in two different body matrices in neurodevelopmental disorders: A preliminary report. J Trace Elem Med Biol 2020; 62: 126553.

28) Silva KG, Pedrini D, Delbem AC, Cannon M. Microhardness and fluoride release of restorative materials in different storage media. Braz Dent J 2007; 18(4): 309-313. 
29) Paschoal MA, Gurgel CV, Rios D, Magalhães AC, Buzalaf MA, Machado MA. Fluoride release profile of a nanofilled resin-modified glass ionomer cement. Braz Dent J 2011; 22(4): 275-279.

30) Kuhn AT, Wilson AD. The dissolution mechanisms of silicate and glass-ionomer dental cements. Biomaterials 1985; 6(6): 378-382.

31) Lidsky TI. Is the Aluminum Hypothesis dead? J Occup Environ Med2014; 56(5 Suppl): 73-79.

32) Cuciureanu R, Urzică A, Voitcu M, Antoniu A. Estimarea aportului zilnic de aluminiu prin consum de alimente [Assessment of daily aluminum intake by food consumption]. Rev Med Chir Soc Med Nat lasi 2000; 104(3): 107-112.

33) Prejac J, Skalny AA, Grabeklis AR, Uzun S, Mimica N, Momčilović B. Assessing the boron nutritional status by analyzing its cummulative frequency distribution in the hair and whole blood. J Trace Elem Med Biol 2018; 45: 50-56.

34) Uluisik I, Karakaya HC, Koc A. Corrigendum to "The importance of boron in biological systems" [J. Trace Elem. Med. Biol. 45 (2018) 156-162]. J Trace Elem Med Biol 2019; 55: 215.

35) González-Weller D, Rubio C, Gutiérrez ÁJ, González GL, Caballero Mesa JM, Revert Gironés C, et al. Dietary intake of barium, bismuth, chromium, lithium, and strontium in a Spanish population (Canary Islands, Spain). Food Chem Toxicol 2013; 62: 856-858.

36) Khandaker M, Vaughan MB, Morris TL, White JJ, Meng Z. Effect of additive particles on mechanical, thermal, and cell functioning properties of poly(methyl methacrylate) cement. Int J Nanomedicine 2014; 27; 9: 2699-2712.

37) Sabokbar A, Fujikawa Y, Murray DW, Athanasou NA. Radio-opaque agents in bone cement increase bone resorption. J Bone Joint Surg Br 1997; 79(1): 129134.

38) Skrajnowska D, Bobrowska-Korczak B. Role of Zinc in Immune System and Anti-Cancer Defense Mechanisms. Nutrients 2019; $22 ; 11(10): 2273$.

39) Hambidge M. The new diatary reference intakes and zinc deficiency: is there a dichotomy? Nutr Today 2001; 36: 278-280.

40) EFSA. Scientific opinion on arsenic in food EFSA J 2009; 7: 1351.

41) Gidlow DA. Lead toxicity. Occup Med (Lond) 2015; 65(5): 348-356.

\section{Tables}

Table 1. Tested materials

\begin{tabular}{|c|c|c|c|c|}
\hline Material & Composition & Manufacturer & Lot number & $\begin{array}{l}\text { Polymerization } \\
\text { type }\end{array}$ \\
\hline $\begin{array}{l}\text { Riva Self Cure } \\
\text { (Traditional Glass } \\
\text { lonomer) }\end{array}$ & Fluoroaluminosilicate glass, acrylic acid polymers, tartaric acid & $\begin{array}{l}\text { SDI Limited, } \\
\text { Bayswater, VIC, } \\
\text { Australia }\end{array}$ & B1403132EG & Chemical \\
\hline $\begin{array}{l}\text { Equia Forte }{ }^{\circledR} \text { Bulk Fill } \\
\text { Glass Hybrid Restorative }\end{array}$ & $\begin{array}{l}\text { Fluoroaluminosilicate glass, polyacrylic acid powder, pigment, } \\
\text { polyacrylic acid, distilled water, polybasic carboxylic acid }\end{array}$ & $\begin{array}{l}\text { GC, Corporation, } \\
\text { Tokyo, Japan }\end{array}$ & 1502071 & Chemical \\
\hline \multirow{5}{*}{$\begin{array}{l}\text { Photac Fil Quick Aplicap } \\
\text { (Resin-modified) }\end{array}$} & Glass powder, surface modified & \multirow{5}{*}{$\begin{array}{l}\text { 3M ESPE, St. } \\
\text { Paul, USA }\end{array}$} & \multirow[t]{5}{*}{618298} & \multirow[t]{5}{*}{ Light } \\
\hline & with 2-propenoic acid, 2 & & & \\
\hline & methyl-.3-(trimethoxysilyl) & & & \\
\hline & propyl ester, bulk material, & & & \\
\hline & N,N-Dimethylbenzocaine & & & \\
\hline Glass Carbomer Fill ${ }^{\mathrm{TM}}$ & Fluoroaluminosilicate glass, apatitie, polyacids & $\begin{array}{l}\text { GCP Dental, } \\
\text { Ridderkerk, } \\
\text { Netherlands }\end{array}$ & 7410293 & Light and heat \\
\hline $\begin{array}{l}\text { Glasiosite, Polyacid- } \\
\text { Modified Composite } \\
\text { Resin (Compomer) }\end{array}$ & $\begin{array}{l}\text { Glassceramics, silicates, initiators, additives, Bisphenol A-glycidyl } \\
\text { methacrylate, Urethane dimethacrylate, Triethylene glycol } \\
\text { dimethacrylate, butylated hydroxyl toluene resin }\end{array}$ & $\begin{array}{l}\text { VOCO, GmbH, } \\
\text { Cuxhaven, } \\
\text { Germany }\end{array}$ & 1521622 & Light \\
\hline
\end{tabular}

Table 2. Light curing devices used in this study

\begin{tabular}{|llll|}
\hline Groups & Device & Manufacturer & Light Intensity \\
\hline Resin-modified GI ${ }^{\#}$ and Compomer & Elipar S10 & 3M ESPE, St. Paul, USA & $1,200 \mathrm{~mW} / \mathrm{cm} 2 \quad 20 \mathrm{~s}$ \\
\hline Glass Carbomer fill & GCP CarboLED thermo-cure lamp & GCP Dental, Ridderkerk, Netherlands & $1,200 \mathrm{~mW} / \mathrm{cm} 2 \quad 60 \mathrm{~s}$ \\
\hline
\end{tabular}

\# Gl: Glass lonomer 
Table 3. The amounts of trace elements released from glass ionomers

\begin{tabular}{|c|c|c|c|c|c|c|c|c|c|c|}
\hline Materials & B & Al & $\mathrm{Fe}^{*}$ & $\mathrm{Ni}$ & $\mathrm{Cu}$ & $\mathrm{Zn}$ & As & $\mathrm{Se}$ & $\mathrm{Sb}$ & $\mathrm{Ba}$ \\
\hline $\begin{array}{l}\text { Traditional } \\
\mathrm{Gl}^{\#}\end{array}$ & $7.86 \pm 1.90^{c}$ & $326 \pm 107^{d}$ & & $0.38 \pm 0.18^{a}$ & $0.21 \pm 0.09^{c}$ & $3.09 \pm 1.18^{b}$ & $0.38 \pm 0.15^{\mathrm{a}}$ & & & $0.80 \pm 0.12$ \\
\hline \multirow[t]{2}{*}{ Bulk fill GI } & $7.58 \pm 3.95^{\mathrm{c}}$ & $1255 \pm 189^{c}$ & & $0.12 \pm 0.05^{c}$ & $0.36 \pm 0.19^{b c}$ & $0.57 \pm 0.18^{d}$ & & $0.16 \pm$ & & $2.81 \pm 0.60$ \\
\hline & & & & & & & & $0.008^{a}$ & & \\
\hline $\begin{array}{l}\text { Resin- } \\
\text { modified } \\
\mathrm{GI}^{\#}\end{array}$ & $7.47 \pm 2.86^{c}$ & $4421 \pm 1607^{a}$ & $0.43 \pm 0.24$ & $0.41 \pm 0.09^{a}$ & $1.18 \pm 0.27^{\mathrm{a}}$ & $6.82 \pm 1.16^{\mathrm{a}}$ & $0.10 \pm 0.06^{b}$ & & $0.09 \pm 0.01^{b}$ & $8.35 \pm 2.05$ \\
\hline $\begin{array}{l}\text { Glass } \\
\text { Carbomer } \\
\text { fill }\end{array}$ & $1221 \pm 272^{a}$ & $2026 \pm 808^{b}$ & & $0.25 \pm 0.09^{b}$ & $0.27 \pm 0.01^{c}$ & $1.99 \pm 1.05^{c}$ & & & & $8.75 \pm 0.66$ \\
\hline \multirow[t]{2}{*}{ Compomer } & $136 \pm 19.3^{b}$ & $88.3 \pm$ & & $0.29 \pm 0.05^{b}$ & $0.49 \pm 0.36^{\mathrm{b}}$ & $1.72 \pm 0.89^{c}$ & & $0.24 \pm 0.19^{a}$ & $4.73 \pm 0.83^{a}$ & $193.7 \pm 31$. \\
\hline & & $1.78^{d}$ & & & & & & & & \\
\hline
\end{tabular}

\# Gl: Glass lonomer; B: Boron, Al: Aluminum, Fe: Iron, Ni: Nickel, Cu: Copper, Zn: Zinc, As: Arsenic, Se: Selenium, Sb: Antimony, Ba: Barium, Pb: Lead; Values are expressed as mean \pm standard deviation $(\mathrm{ppb}=\mu \mathrm{g} / \mathrm{L}) ;{ }^{*}$ No statistical analysis; There is no statistical difference between same letters in same column.

Table 4. $\mathrm{pH}$ and electrical conductivity values

\begin{tabular}{|llllll|}
\hline Materials & Traditional GI & Bulk fill GI $^{\#}$ & Resin-modified Gl & Glass Carbomer fill & Compomer \\
$\mathrm{pH}$ & $6.33 \pm 0.15^{\mathrm{a}}$ & $6.36 \pm 0.09^{\mathrm{a}}$ & $6.34 \pm 0.05^{\mathrm{a}}$ & $6.39 \pm 0.04^{\mathrm{a}}$ & $5.62 \pm 0.29^{\mathrm{b}}$ \\
\hline Electrical conductivity & $21.8 \pm 1.7^{\mathrm{d}}$ & $33.6 \pm 4.3^{\mathrm{c}}$ & $58.7 \pm 8.5^{\mathrm{a}}$ & $43.3 \pm 5.8^{\mathrm{b}}$ & $4.6 \pm 0.94^{\mathrm{e}}$ \\
\hline
\end{tabular}

\# Gl: Glass lonomer; There is no statistical difference between same letters in same line 